\title{
Influence of carbon precursor on porosity, surface composition and catalytic behaviour of CMK-3 in oxidative dehydrogenation of propane to propene
}

\author{
Adam Wegrzyniak $^{1} \cdot$ Sebastian Jarczewski $^{2} \cdot$ Piotr Kuśtrowski $^{2} \cdot$ Piotr Michorczyk $^{1}$
}

Published online: 24 July 2017

(c) The Author(s) 2017. This article is an open access publication

\begin{abstract}
Ordered mesoporous CMK-3 carbon replicas were synthesized by infiltration of mesopores present in a SBA-15 silica template with two different carbon precursors, i.e. sucrose and poly(furfuryl alcohol). The obtained composites were carbonized under an inert gas atmosphere at $550,650,750$ and $850^{\circ} \mathrm{C}$, and the template was etched with a HF solution. The final carbon replicas were analyzed by various physicochemical techniques, including low-temperature $\mathrm{N}_{2}$ adsorption, X-ray diffraction, X-ray photoelectron spectroscopy, scanning and transmission electron microscopy, and tested as catalysts in the oxidative dehydrogenation of propane (ODP) at $450^{\circ} \mathrm{C}$. Both series of materials differed strongly with respect to their porosity, but showed very similar surface composition determined by XPS. Higher porosity of CMK-3 prepared using the sucrose precursor influenced propane conversion and selectivity to propene. Furthermore, oxygen containing groups (e.g. carbonyl-type) were found to be less sensitive to the type of carbon precursor than to the ODP reaction conditions.
\end{abstract}

Keywords Oxidative dehydrogenation $\cdot$ Propene $\cdot$ Carbon replica $\cdot$ CMK-3

Piotr Michorczyk

pmichor@pk.edu.pl

1 Institute of Organic Chemistry and Technology, Cracow University of Technology, Warszawska 24, 31-155 Kraków, Poland

2 Faculty of Chemistry, Jagiellonian University, Gronostajowa 2, 30-387 Kraków, Poland

\section{Introduction}

Propylene is one of the most important raw materials in the chemical industry. It is mainly used as an intermediate in the production of polypropylene, propylene oxide and acrylonitrile [1]. Due to the rapidly growing plastics industry, the demand for propylene has still increased. Nowadays, the highest amounts of propylene are obtained in steam cracking and fluid catalytic cracking. Nevertheless, on-purpose technologies of propylene production, including olefin metathesis, methanol to olefins and methanol to propylene processes as well as dehydrogenation of propane (DHP), have been intensively developed [1-3].

The alkane dehydrogenation is an equilibrium-controlled, endothermic process. Therefore, high temperatures and low pressures are required to achieve reasonable olefin yields. Temperatures needed to convert light alkanes are significantly higher compared to those used in dehydrogenation of long chain paraffins. Increasing reaction temperatures result in higher equilibrium conversions, but also in acceleration of side reactions. To keep the production of olefins economically viable, the process must be therefore carried out at limited temperatures giving a relatively high selectivity to the desirable product. The decrease in the reaction temperature can be achieved by an addition of oxidizing agent. Therefore, the catalytic oxidative dehydrogenation of propane to propylene (ODP) has received a special attention as a promising alternative to the DHP $[2,4$, 5]. It should however be kept in mind that the ODP process has several limitations hampering its commercialization. For instance, propene is more reactive than propane, and in consequence significant amounts of $\mathrm{CO}_{\mathrm{x}}$ are formed due to deep oxidation of this olefin. The development of catalysts, which would be highly selective to propene at reasonable per-pass conversion of propane, is still a great challenge. 
Carbon materials with a high surface area and large pore volume have found an increasing number of applications in catalysis, adsorption, separation or electrochemistry [6-14]. Very promising results were collected over metal-free carbon nanomaterials (e.g. nanotubes, nanorods or onion-type structures) in the oxidative dehydrogenation of hydrocarbons, especially in the oxidative dehydrogenation of ethylbenzene to styrene [11-13]. For example, over CMK-3 carbon with a rod-type skeleton structure, at temperature as low as $400{ }^{\circ} \mathrm{C}$, the stable ethylbenzene conversion of $69.0 \%$ at the yield and selectivity to styrene of 52.4 and $76.0 \%$, respectively, were achieved [12].

It was shown that the oxidative dehydrogenation of hydrocarbons in the presence of metal-free carbon catalysts proceeds according to the mechanism, in which oxygencontaining surface groups are active in redox cycles (as shown in Fig. 1). According to this concept, quinoidictype surface functionalities are active sites in the oxidative dehydrogenation of hydrocarbons [11]. The concentration of these moieties can be controlled either by an appropriate selection of synthesis conditions or by post-synthesis surface modification (e.g. surface oxidation with air, $\mathrm{HNO}_{3}$, $\mathrm{H}_{2} \mathrm{O}_{2}$ etc.) [15].

In our previous work we have found that pure CMK-3 exhibits reasonable catalytic performance in ODP [6]. An important role of stable oxygen-containing surface groups for activation of propane was confirmed. In this work, we discuss an influence of type of carbon precursor (sucrose and poly(furfuryl alcohol)) as well as thermal treatment conditions on the catalytic performance of CMK-3 carbons produced by reverse replication of a SBA-15 silica

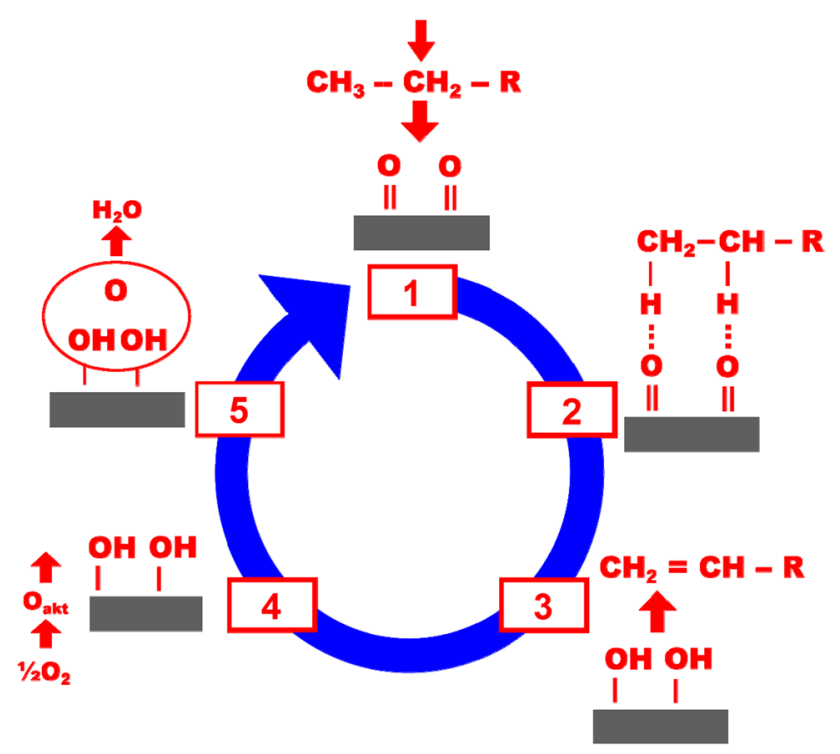

Fig. 1 Proposed mechanism of oxidative dehydrogenation of hydrocarbons over carbon materials (adopted from [11]) template. The most important properties of the obtained materials affecting their catalytic performance in the ODP are indicated.

\section{Experimental}

\subsection{Preparation of catalysts}

Mesoporous SBA-15 silica was prepared according to the procedure described previously by Michorczyk et al. [16]. Briefly, $8 \mathrm{~g}$ of Pluronic 123 (Aldrich) was dissolved in a solution containing $120 \mathrm{~g}$ of $2 \mathrm{M} \mathrm{HCl}$ and $60 \mathrm{~g}$ of distilled water. The mixture was stirred at $35^{\circ} \mathrm{C}(1000 \mathrm{rpm})$ until the complete dissolution of copolymer. Next, $17 \mathrm{~g}$ of TEOS (98\%, Aldrich) was added. The mixture was stirred at $35^{\circ} \mathrm{C}$ for $20 \mathrm{~h}(400 \mathrm{rpm})$ and aged at $90{ }^{\circ} \mathrm{C}$ for $24 \mathrm{~h}$, filtered without washing and then dried. Finally, the obtained white solid was calcined in air by a linear increase in temperature from 30 to $550{ }^{\circ} \mathrm{C}$ during $9 \mathrm{~h}$, and then keeping at this temperature for further $12 \mathrm{~h}$.

SBA-15 was used as a hard template to the synthesis of CMK-3 carbon by the structure replication of mesoporous silica template. Two different carbon precursors, i.e. sucrose (CMK-3s) and poly(furfuryl alcohol) (CMK-3f), were used. The CMK-3s material was obtained by the incipient wetness technique [17]. $1 \mathrm{~g}$ of SBA-15 was impregnated with a solution containing $5 \mathrm{~g}$ of water, $1.25 \mathrm{~g}$ of sucrose $(\mathrm{POCH})$ and $0.14 \mathrm{~g}$ of sulfuric acid $(95 \%, \mathrm{POCH})$. The impregnated silica was dried in two steps: at $100{ }^{\circ} \mathrm{C}$ for $6 \mathrm{~h}$ and then at $160{ }^{\circ} \mathrm{C}$ for another $6 \mathrm{~h}$. Subsequently, the impregnation procedure was repeated. In the second impregnation step, a solution containing $3 \mathrm{~g}$ of water, $0.8 \mathrm{~g}$ of sucrose and $0.09 \mathrm{~g}$ of sulphuric acid was introduced into the previously modified solid. Then, the drying procedure was repeated. The carbon-silica composite was subsequently thermally treated under an inert gas atmosphere of $\mathrm{N}_{2}$ at various temperatures $-550,650,750$ or $850{ }^{\circ} \mathrm{C}$ with a temperature rate of $1{ }^{\circ} \mathrm{C} / \mathrm{min}$. Finally, the silica template was removed by etching with $10 \%$ hydrofluoric acid solution. The prepared CMK-3s carbon was washed with deionized water and dried at $120^{\circ} \mathrm{C}$ for $24 \mathrm{~h}$.

The CMK-3f carbon was synthesized using poly(furfuryl alcohol) as the carbon source according to the procedure described by Botas et al. [18]. $1 \mathrm{~g}$ of SBA-15 was impregnated with a solution containing $0.012 \mathrm{~g}$ of oxalic acid (POCH) and $3 \mathrm{ml}$ of furfuryl alcohol (98\%, Acros Organics). The resulting sample was dried at $50{ }^{\circ} \mathrm{C}$ for $24 \mathrm{~h}$ and then at $90{ }^{\circ} \mathrm{C}$ for $48 \mathrm{~h}$. Subsequently, carbonization was performed at $150{ }^{\circ} \mathrm{C}$ for $3 \mathrm{~h}$, followed by an increasing temperature to $300{ }^{\circ} \mathrm{C}$ at a heating rate of $1{ }^{\circ} \mathrm{C} / \mathrm{min}$, and then at $5^{\circ} \mathrm{C} / \mathrm{min}$ to final temperature $\left(550,650,750\right.$ or $\left.850{ }^{\circ} \mathrm{C}\right)$, at 
which the sample was kept for $3 \mathrm{~h}$. The procedure of $\mathrm{SiO}_{2}$ elimination was the same like in the case of CMK-3s.

The notation of CMK-3sx and CMK-3fx (where: $\mathrm{x}=550,650,750$ and 850) was applied for the thermally treated sucrose- and poly(furfuryl alcohol)-based materials, respectively.

\subsection{Characterization methods}

Low-temperature $\mathrm{N}_{2}$ adsorption-desorption isotherms were measured at $-196{ }^{\circ} \mathrm{C}$ using a Micromeritics ASAP 2020 adsorption analyzer. Before analyses, samples were degassed at $250{ }^{\circ} \mathrm{C}$ under vacuum. Specific surface areas $\left(\mathrm{S}_{\mathrm{BET}}\right)$ were calculated using the Brunauer-Emmett-Teller (BET) theory. Pore size distributions were measured using the Barret-Joyner-Halenda (BJH) model, whereas total pore volumes $\left(\mathrm{V}_{\text {total }}\right)$ were determined based on amounts of nitrogen adsorbed at $\mathrm{p} / \mathrm{p}_{0}=0.95-0.98$.

Structure of the prepared materials was characterized by powder X-ray diffraction (XRD) using a Bruker D2 Phaser instrument. Diffractograms were collected in the $2 \theta$ range from 0.5 to $10.0^{\circ}$ with a step of $0.02^{\circ}$ and $1 \mathrm{~s} \mathrm{counting} \mathrm{time}$ per the step.

Scanning electron microscope (SEM) images were taken on a Merlin Gemini II microscope equipped with a field emission gun. Prior to the observation a sample was vapour-deposited with carbon. Transmission electron microscopy (TEM) images were collected on a Tecnai G2 TWIN instrument equipped with lanthanum hexaboride $\left(\mathrm{LaB}_{6}\right)$ cathodes. Samples were suspended in water and then deposited onto a carbon grid.

The surface composition of samples was investigated with X-ray photoelectron spectroscopy (XPS) using a Prevac photoelectron spectrometer equipped with a hemispherical analyzer (VG SCIENTA R3000). The spectra were taken using a monochromatized aluminum source Al $\mathrm{K} \alpha(E=1486.6 \mathrm{eV})$. The base pressure in the analytical chamber was $5 \times 10^{-9}$ mbar. The binding energy scale was calibrated using the $\mathrm{Au} 4 \mathrm{f}_{7 / 2}$ line of a cleaned gold sample at $84.0 \mathrm{eV}$. The surface composition was analyzed taking into account the areas and binding energies of $\mathrm{C} 1 \mathrm{~s}$ and O 1 s core levels. The spectra were fitted using CasaXPS software.

\subsection{Catalytic tests}

The oxidative dehydrogenation of propane (99.6 vol\%, Linde) to propene was carried out in the presence of $\mathrm{O}_{2}$ (99.96 vol\%, Linde) in a flow-type quartz microreactor. A mass of each catalyst (with grain size in the range $0.2-0.3 \mathrm{~mm}$ ) was $200 \mathrm{mg}$. The total flow rate of the feed was $30 \mathrm{~cm}^{3} / \mathrm{min}$ at the $\mathrm{C}_{3} \mathrm{H}_{8}: \mathrm{He}: \mathrm{O}_{2}$ molar ratio of $2: 27: 1$. The reaction was carried out at $450{ }^{\circ} \mathrm{C}$ under atmospheric pressure, and the catalyst was used without dilution. Directly before a catalytic test, the catalyst was preheated in order to degassing at the reaction temperature in a $\mathrm{He}$ flow $\left(30 \mathrm{~cm}^{3} / \mathrm{min}\right)$ for $0.5 \mathrm{~h}$. The reaction products were analyzed using an Agilent $6890 \mathrm{~N}$ gas chromatograph equipped with two columns (Hayesep Q and Molecular Sieve $5 \mathrm{~A})$. Propene yield $\left(Y_{p}\right)$, propane conversion $\left(X_{p}\right)$ and selectivity to products $\left(S_{i}\right)$ were calculated as described:

$Y_{p}=\frac{n_{C_{3} H_{6}, \text { outlet }}}{n_{C_{3} H_{8}, \text { inlet }}} \times 100 \%$

$X_{p}=\frac{n_{C_{3} H_{8}, \text { inlet }}-n_{C_{3} H_{8}, \text { outlet }}}{n_{C_{3} H_{8}, \text { inlet }}} \times 100 \%$

$S_{i}=\frac{a_{i} \times n_{i}}{3} \times \frac{100 \%}{n_{C_{3} H_{8} \text {,inlet }}-n_{C_{3} H_{8}, \text { outlet }}}$

where $n_{C_{3} H_{8}, \text { inlet }}, n_{C_{3} H_{8} \text {,outlet }}$ are numbers of propane moles in inlet and outlet of the reactor, $n_{C_{3} H_{6}, \text { outlet }}$ is a number of moles of produced propene, $a_{i}$ is a number of carbon atoms in $i$ product, $n_{i}$ is a number of moles of $i$ product.

\section{Results and discussion}

\subsection{Physicochemical properties of CMK-3 catalysts}

Figure 2a, c show the low temperature nitrogen adsorption-desorption isotherms recorded for both CMK-3s and CMK-3f materials. According to the IUPAC classification the isotherms are of type IV, which is characteristic for mesoporous solids. A dominant role of ordered mesopores in the porosity of the CMK-3 materials is also confirmed by the BJH pore size distributions (Fig. 2b, d). For both series of the carbon materials a majority of mesopores has diameters in the range of 2-8 $\mathrm{nm}$. Nevertheless, carbonization at the lowest temperature $\left(550{ }^{\circ} \mathrm{C}\right)$ leads to a disappearance of mesoporosity. The most ordered hexagonal structure is obtained after carbonization at $750{ }^{\circ} \mathrm{C}$.

Table 1 summarizes the specific surface areas as well as pore volumes for both series of CMK-3 materials carbonized at different temperatures. The CMK-3s materials have considerably higher surface areas and larger pore volumes compared to the CMK-3f ones. This effect should be strongly connected to the carbon precursor used. Furthermore, the results reported in Table 1 indicate a higher contribution of microporosity in the case of the CMK-3s materials. It is most likely due to the thermal decomposition of sucrose precursor which forms more microporous carbon materials. Possible differences in microporosity of both prepared replicas are presented in Fig. 3 . 
Fig. 2 Low temperature nitrogen adsorption-desorption isotherms $(\mathbf{a}, \mathbf{c})$ and $\mathrm{BJH}$ pore size distributions $(\mathbf{b}, \mathbf{d})$ for CMK-3s and CMK-3f materials
Table 1 Textural properties of SBA-15 template and corresponding CMK-3 replicas
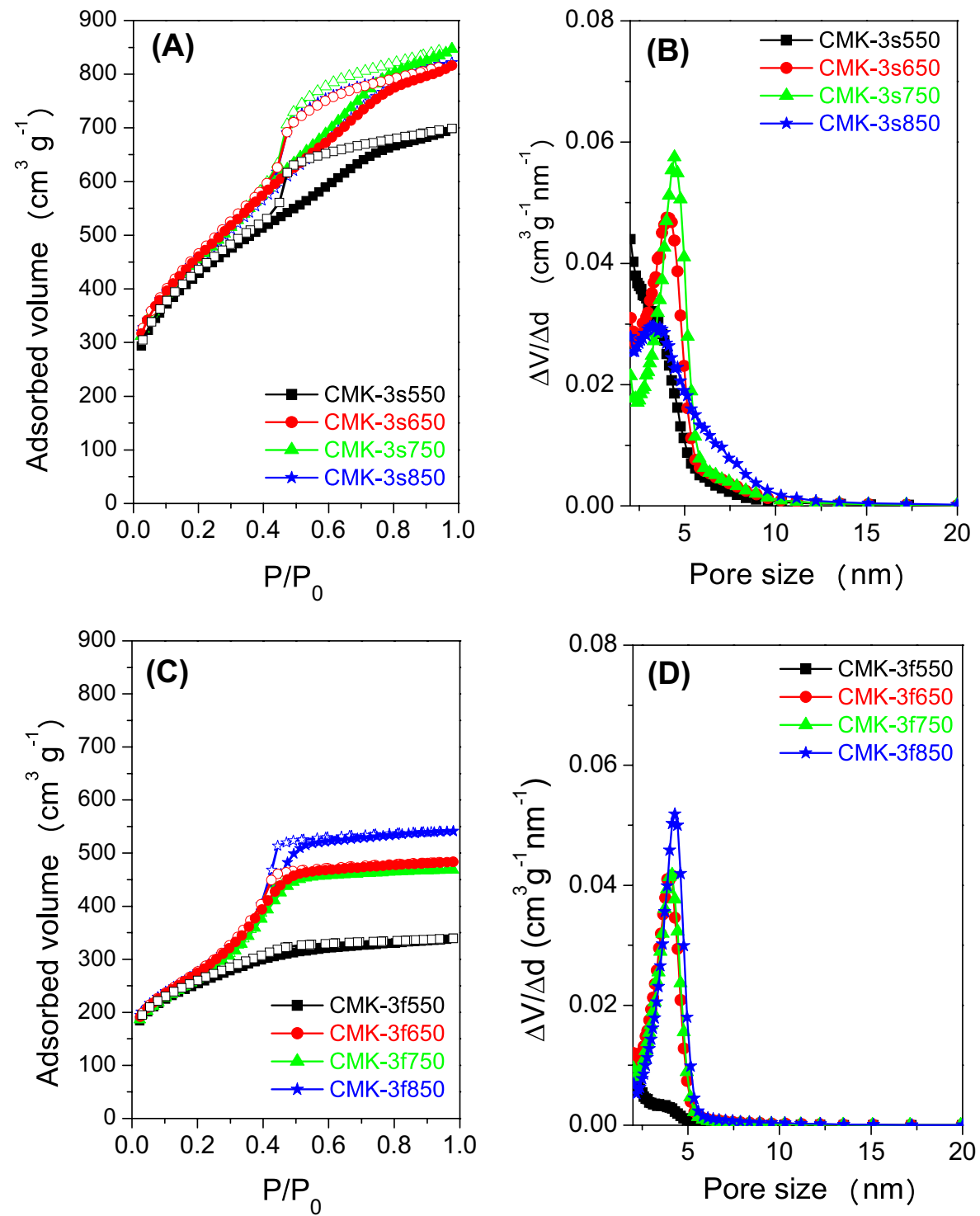

\begin{tabular}{lllll}
\hline Sample & $\mathrm{S}_{\text {BET }}\left(\mathrm{m}^{2} \mathrm{~g}^{-1}\right)$ & $\mathrm{V}_{\text {micro }}\left(\mathrm{cm}^{3} \mathrm{~g}^{-1}\right)$ & $\mathrm{V}_{\text {meso }}\left(\mathrm{cm}^{3} \mathrm{~g}^{-1}\right)$ & $\mathrm{V}_{\text {total }}\left(\mathrm{cm}^{3} \mathrm{~g}^{-1}\right)$ \\
\hline SBA-15 & 694 & 0.04 & 0.81 & 0.85 \\
CMK-3s550 & 1653 & 0.11 & 1.00 & 1.11 \\
CMK-3s650 & 1684 & 0.08 & 1.28 & 1.36 \\
CMK-3s750 & 1608 & 0.07 & 1.31 & 1.38 \\
CMK-3s850 & 1686 & 0.09 & 1.13 & 1.22 \\
CMK-3f550 & 904 & 0.01 & 0.51 & 0.52 \\
CMK-3f650 & 947 & 0.01 & 0.74 & 0.75 \\
CMK-3f750 & 909 & 0.01 & 0.71 & 0.72 \\
CMK-3f850 & 964 & 0.01 & 0.83 & 0.84 \\
\hline
\end{tabular}

The uniform pore structure of the SBA-15 hard template and carbon replicas carbonized at $750{ }^{\circ} \mathrm{C}$ (CMK-3s750 and CMK-3f750) was confirmed by the TEM micrographs, as shown in Fig. 4 (right panels). Moreover, the SEM images
(Fig. 4, left panels) reveal that both hard template and CMK-3 materials consist of aggregated, rod-type microparticles. These findings indicate that the synthesized CMK-3 carbon materials are inverse replicas of SBA-15. The 

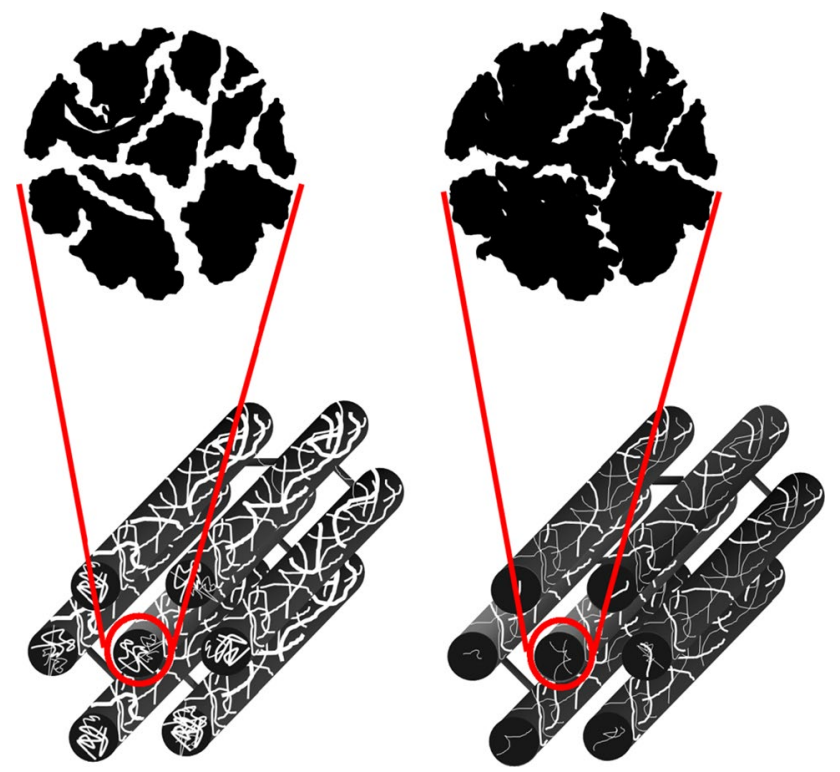

Fig. 3 Possible differences in porosity of CMK-3s (left) and CMK3f (right) caused by various behaviours of carbon precursors during thermal treatment
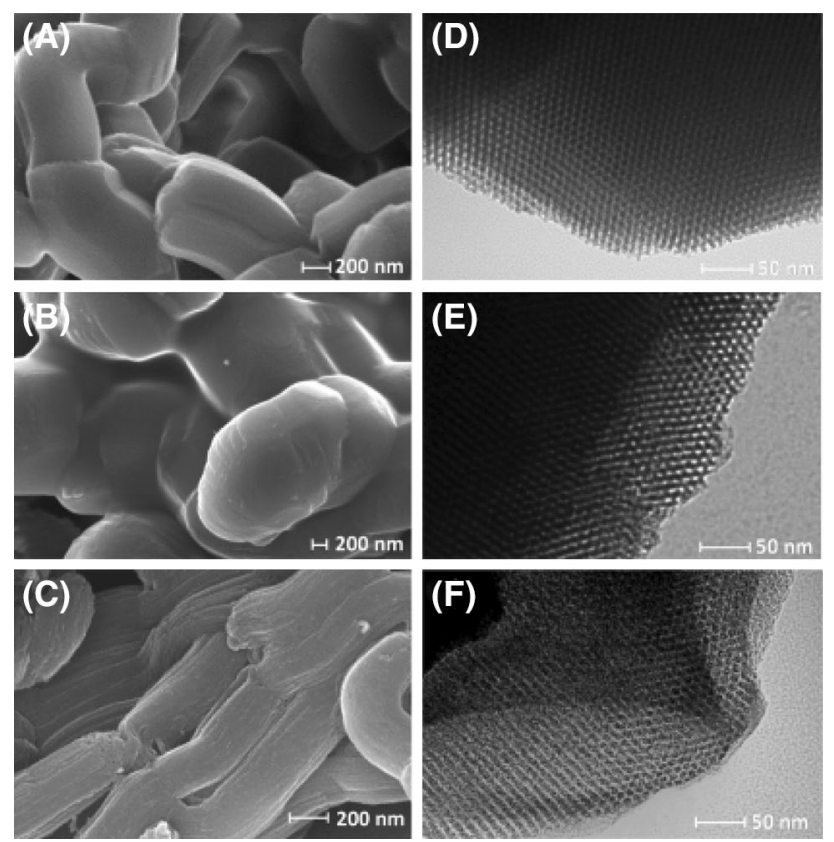

Fig. 4 SEM (left panel) and TEM (right panel) images of SBA-15 (a, d), CMK-3f750 (b, e), and CMK-3s750 (c, f)

well-ordered mesoporous structure of the materials was also confirmed by XRD. In Fig. 5a, b the recorded XRD patterns of the studied carbon samples are presented. In the low $2 \theta$ range of $0.5-5^{\circ}$ all carbon catalysts show three diffraction lines indexed to (100), (110), and (200), which are characteristic of hexagonally ordered, mesoporous materials. The most intense (100) peak is observed in the materials carbonized at $750{ }^{\circ} \mathrm{C}$. It can be found that the intensity of this reflection decreases after carbonization at other temperatures. This confirms gradual disordering of the CMK-3 structure, which is especially distinct for the samples carbonized at $550{ }^{\circ} \mathrm{C}$ as has been previously discussed for the results of low-temperature $\mathrm{N}_{2}$ adsorption.

The surface composition of the carbon materials obtained by the thermal treatment at various temperatures was studied by XPS. The collected $\mathrm{C} 1 \mathrm{~s}$ and $\mathrm{O} 1 \mathrm{~s}$ spectra are shown in Fig. 6a (CMK-3s) and 6b (CMK-3f), whereas the contents of identified surface functionalities are presented in Table 2. In the C 1 spectra five different signals are observed, which correspond to: (i) aromatic and aliphatic carbon $(284.4 \pm 0.1 \mathrm{eV})$, (ii) single C-O bonds (286.3 $\pm 0.1 \mathrm{eV})$, (iii) double $\mathrm{C}=\mathrm{O}$ bonds $(287.3 \pm 0.1 \mathrm{eV})$, (iv) carboxyl species $(288.4 \pm 0.1 \mathrm{eV})$, and (v) very weak shake-up satellite due to a $\pi-\pi^{*}$ transition or a plasmon peak $(290.0 \pm 0.2 \mathrm{eV})$ [19-21]. Accordingly, for the O 1s spectra four components are distinguished, which can be assigned to oxygen in: (i) $\mathrm{C}=\mathrm{O}$ bonds $(531.2 \pm 0.2 \mathrm{eV}$ ), (ii) $\mathrm{C}-\mathrm{O}$ bonds and $\mathrm{C}=\mathrm{O}$ in carboxyl functionalities $(533.3 \pm 0.2 \mathrm{eV}$ ), (iii) $\mathrm{C}-\mathrm{OH}$ in carboxyl functionalities $(534.5 \pm 0.2 \mathrm{eV})$, and (iv) adsorbed water $(536.9 \pm 0.2 \mathrm{eV})$.

It can be found that for both series of CMK-3 materials the total concentration of oxygen-containing surface groups decreases with the carbonization temperature. On the other hand, the contribution of carbonyl-type groups in the samples carbonized at $550{ }^{\circ} \mathrm{C}$ is low, and increases after the carbonization at $650{ }^{\circ} \mathrm{C}$. This effect is especially distinct for the PFA-based carbon replicas. However, it should be kept in mind that the entire decomposition of poly(furfuryl alcohol) demands temperatures higher than $550{ }^{\circ} \mathrm{C}$ as was previously shown for the CMK-1 replicas obtained from the MCM-48 template filled with PFA and carbonized at a wide range of temperature [22]. Moreover, a comparison of surface compositions for the CMK-3 materials obtained using two different carbon precursors reveals that the concentration of oxygen-containing surface groups is higher for the CMK-3s materials, while the content of catalytically important carbonyl-type groups is slightly higher in the case of CMK-3f catalysts.

\subsection{Catalytic activity of CMK-3 catalysts}

The results collected at the initial period of the reaction are shown in Table 3. In the presence of CMK-3s carbonized at different temperatures the initial conversion of propane was in the range of $15-25 \%$, whereas for CMK-3f it did not exceed $15 \%$ in any case. However, the calculation of specific activity, expressed as a number of moles of propane converted during $1 \mathrm{~s}$ on $1 \mathrm{~m}^{2}$ of surface, reveals that this parameter is only slightly better for the CMK-3f catalysts. 
Fig. 5 Powder XRD patterns of CMK-3s (a) and CMK-3f (b) carbon materials
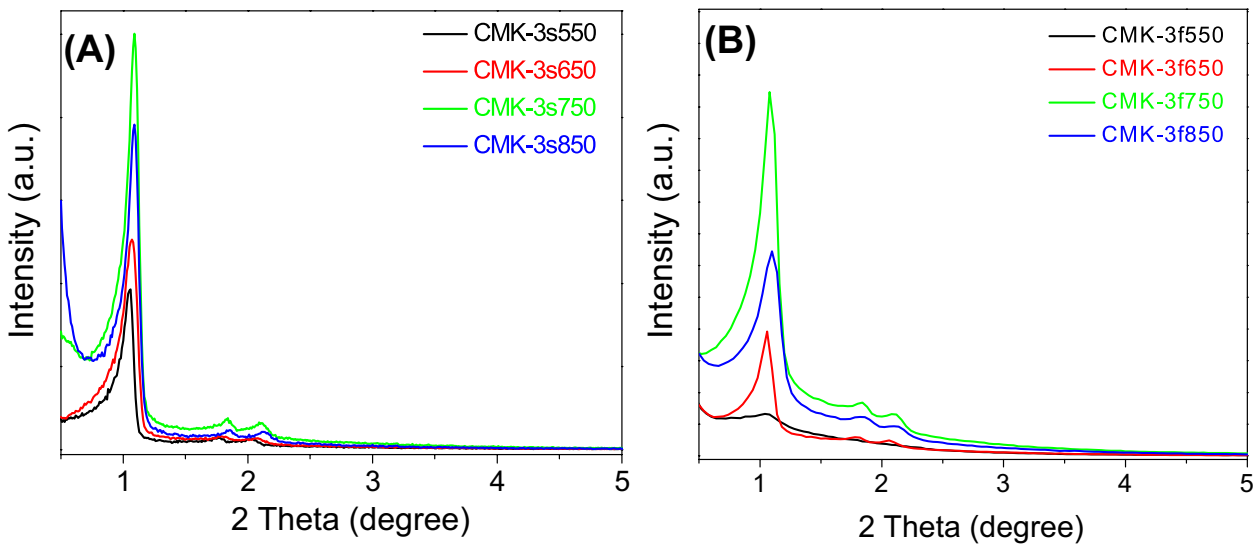

The catalytic activity of different carbonaceous materials in the oxidative dehydrogenation of hydrocarbons is usually attributed to the presence of carbonyl-type groups (cf. Fig. 1). In a subsequent step, oxygen chemisorbed on basal planes of the graphite layers diffuses to hydroxyl groups and oxidizes them with a release of water molecule [6, 11-13]. Our XPS results confirm that the concentration of carbonyl-type groups is only slightly higher in the case of the CMK-3f materials, which reflects in an insignificant difference of specific activity determined for both series of the studied catalysts.

Over all studied CMK-3 materials propene and carbon oxides $\left(\mathrm{CO}\right.$ and $\left.\mathrm{CO}_{2}\right)$ were the main reaction products. The selectivity to propene was higher in the ODP reaction carried out over the CMK-3f materials. In the case of CMK-3f carbonized at $850{ }^{\circ} \mathrm{C}$ the initial propene selectivity reached $48 \%$. The observed difference in selectivity over the CMK-3 materials can be attributed to the light substrateproduct reactivity. Typically, in oxidative dehydrogenation of hydrocarbons a higher conversion leads to a higher concentration of more reactive products (like propene) that are oxidized to $\mathrm{CO}_{\mathrm{x}}$ in consecutive reactions. That is reason why the higher conversion of propane over the CMK-3s samples leads to the decrease in the propene selectivity.

Moreover, it should be pointed that carbon oxides could be formed either by the total oxidation of propane and the combustion of catalyst. Our previous studies for the sucrose-derived CMK-3 replicas showed that during the ODP performed at $450{ }^{\circ} \mathrm{C}$ these materials gradually loss the mass due to the reaction with oxygen [6]. However, as revealed by thermogravimetry, the burning of CMK-3 at low temperature (below $450{ }^{\circ} \mathrm{C}$ ) and in the absence of metals (like $\mathrm{Cr}$ ) is negligible [6,9]. Moreover, during the ODP other hydrocarbon by-products, such as methane, ethane and ethene, are produced with a total selectivity below $5 \%$.

Figure 7 shows the changes in the propane conversion observed with increasing time-on-stream (TOS) over the studied carbon catalysts. For each series of materials obtained from the same precursor and treated at different temperatures, the conversion of propane varies only during the initial $30 \mathrm{~min}$ on-stream. After this initial period, the differences in the propane conversion observed for the catalysts prepared at various carbonization temperatures gradually decrease. Ordered mesoporous carbon materials synthesized by various methods and pre-treated at different conditions exhibited earlier a very similar behaviour in the oxidative dehydrogenation of ethylbenzene [21]. It was found that during this process the surface oxygencontaining species generated during the synthesis and subsequent modifications were lost by decomposition and/or re-arrangement (connected with the formation of carbon deposit) and, in consequence, similar activity was observed after some hours on stream over all materials [21, 23, 24].

Figure 8 summarizes the variations in selectivity to propene vs. TOS. Over CMK-3f higher initial selectivity to propene is gradually minimized during the ODP process. After about $60 \mathrm{~min}$ on stream over the CMK-3s and CMK3f materials selectivity to propene changes in a narrow range between 30 to $40 \%$.

Expecting a fast transformation of surface moieties, we studied the surface composition of the spent catalysts after the ODP. In Fig. 9 the concentration of oxygen-containing groups in the materials before and after the catalytic reaction is compared. Evidently, during the catalytic run the surface composition of the carbon materials changes drastically. A huge increase in the concentration of the oxygencontaining species, formed in the reaction environment, is found (with exception of CMK-3f550, which is derived from incompletely decomposed PFA). This clearly indicates that a majority of the catalytically active carbonyltype groups is formed in contact with oxygen from the reaction mixture during the initial step of ODP.

Taking into account the observed changes in the surface composition and the differences in textural parameters of the studied materials, we can conclude that their catalytic performance in the ODP is strongly influenced by the type 

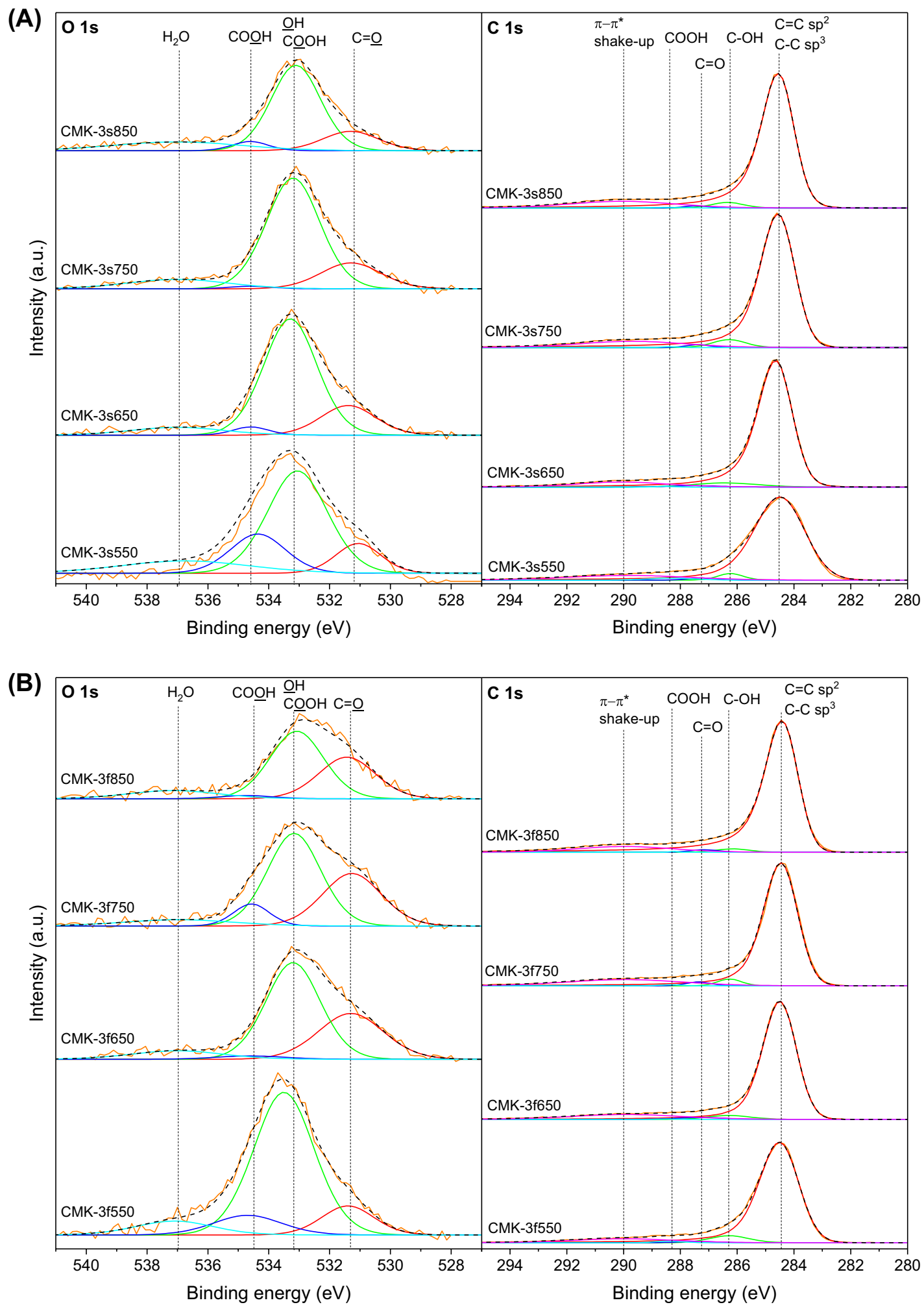

Fig. 6 O 1s and C 1s XPS spectra collected for CMK-3s (a) and CMK-3f (b) carbon materials

of the carbon precursor. The higher surface areas of the CMK-3s materials obviously result in the higher conversion of propane that has impact on selectivity to propene in the ODP reaction. On the other hand, the type of carbon precursor has only slight influence on the surface composition that is modified at the beginning of the reaction. 
Table 2 Surface composition of mesoporous CMK-3 carbons determined by XPS
Table 3 Catalytic performance of mesoporous CMK-3 carbons in the oxidative dehydrogenation of propane at $450{ }^{\circ} \mathrm{C}$

\begin{tabular}{|c|c|c|c|c|c|c|c|c|c|c|}
\hline \multirow[t]{2}{*}{ Sample } & \multicolumn{5}{|c|}{ Carbon (at.\%) } & \multicolumn{5}{|c|}{ Oxygen (at.\%) } \\
\hline & $\begin{array}{l}\mathrm{C}=\mathrm{C} \\
\mathrm{sp}^{2} \mathrm{C}-\mathrm{C} \\
\mathrm{sp}^{3 \mathrm{a}}\end{array}$ & $\underline{\mathrm{C}}-\mathrm{OH}^{\mathrm{b}}$ & $\underline{\mathrm{C}}=\mathrm{O}^{\mathrm{c}}$ & $\underline{\mathrm{COOH}}^{\mathrm{d}}$ & Total & $\mathrm{C}=\underline{\mathrm{O}}^{\mathrm{e}}$ & $\mathrm{C}-\underline{\mathrm{O}} \mathrm{H}, \mathrm{C}^{\mathrm{OOOH}}{ }^{\mathrm{f}}$ & $\mathrm{CO} \underline{\mathrm{O}} \mathrm{H}^{\mathrm{g}}$ & $\mathrm{H}_{2} \mathrm{O}^{\mathrm{h}}$ & Total \\
\hline CMK-3s550 & 86.56 & 2.79 & 1.00 & 1.53 & 91.88 & 0.98 & 4.43 & 1.56 & 1.16 & 8.13 \\
\hline CMK-3s650 & 88.22 & 4.35 & 1.12 & 0.20 & 93.89 & 1.12 & 4.29 & 0.20 & 0.50 & 6.11 \\
\hline CMK-3s750 & 89.45 & 3.86 & 1.00 & 0.19 & 94.50 & 1.01 & 3.81 & 0.07 & 0.62 & 5.51 \\
\hline CMK-3s850 & 91.81 & 2.70 & 0.79 & 0.25 & 95.55 & 0.71 & 2.77 & 0.22 & 0.75 & 4.45 \\
\hline CMK-3f550 & 86.21 & 4.91 & 0.88 & 0.84 & 92.84 & 0.87 & 4.91 & 0.76 & 0.62 & 7.16 \\
\hline CMK-3f650 & 89.52 & 3.16 & 1.75 & 0.17 & 94.60 & 1.75 & 3.07 & 0.14 & 0.45 & 5.41 \\
\hline CMK-3f750 & 90.32 & 2.68 & 1.60 & 0.38 & 94.98 & 1.63 & 2.60 & 0.42 & 0.36 & 5.01 \\
\hline CMK-3f850 & 93.54 & 1.78 & 1.15 & 0.11 & 96.58 & 1.17 & 1.80 & 0.09 & 0.37 & 3.43 \\
\hline
\end{tabular}

B.E. [eV]: ${ }^{\mathrm{a}} 284.3-284.5,{ }^{\mathrm{b}} 286.2-286.4,{ }^{\mathrm{c}} 287.2-287.4,{ }^{\mathrm{d}} 288.3-288.5,{ }^{\mathrm{e}} 531.1-531.4,{ }^{\mathrm{f}} 533.1-533.5,{ }^{\mathrm{g}} 534.4-$ 534.7, ${ }^{\mathrm{h}} 536.8-537.1$

\begin{tabular}{|c|c|c|c|c|c|c|c|c|}
\hline \multirow[t]{2}{*}{ Sample } & \multirow{2}{*}{$\begin{array}{l}\text { Specific activity } \\
\left(\mathrm{mol} \mathrm{C}_{3} \mathrm{H}_{8} / \mathrm{s} \mathrm{m}^{2}\right)\end{array}$} & \multirow{2}{*}{$\begin{array}{l}\text { Conversion (\%) } \\
\mathrm{C}_{3} \mathrm{H}_{8}\end{array}$} & \multirow{2}{*}{$\begin{array}{l}\text { Yield (\%) } \\
\mathrm{C}_{3} \mathrm{H}_{6}\end{array}$} & \multicolumn{5}{|c|}{ Selectivity (\%) } \\
\hline & & & & $\mathrm{C}_{3} \mathrm{H}_{6}$ & $\mathrm{C}_{2} \mathrm{H}_{6}$ & $\mathrm{C}_{2} \mathrm{H}_{4}$ & $\mathrm{CH}_{4}$ & $\mathrm{CO}_{\mathrm{x}}$ \\
\hline CMK-3s550 & $7.11 \times 10^{-10}$ & 15.8 & 5.4 & 34.1 & 0.8 & 0.9 & 1.7 & 62.5 \\
\hline CMK-3s650 & $1.07 \times 10^{-9}$ & 24.3 & 7.9 & 32.6 & 0.3 & 1.9 & 2.4 & 62.8 \\
\hline CMK-3s750 & $1.08 \times 10^{-9}$ & 23.3 & 8.7 & 37.4 & 0.4 & 3.0 & 0.5 & 58.7 \\
\hline CMK-3s850 & $9.89 \times 10^{-10}$ & 22.4 & 7.1 & 34.7 & 0.0 & 1.9 & 0.4 & 63.0 \\
\hline CMK-3f550 & $9.38 \times 10^{-10}$ & 11.4 & 4.4 & 38.6 & 0.5 & 1.6 & 0.2 & 59.1 \\
\hline CMK-3f650 & $1.15 \times 10^{-9}$ & 14.7 & 5.6 & 37.9 & 0.2 & 1.6 & 0.3 & 65.0 \\
\hline CMK-3f750 & $1.12 \times 10^{-9}$ & 13.7 & 5.2 & 38.2 & 0.2 & 1.8 & 0.2 & 59.6 \\
\hline CMK-3f850 & $1.03 \times 10^{-9}$ & 13.3 & 6.5 & 48.6 & 0.2 & 2.3 & 0.3 & 48.6 \\
\hline
\end{tabular}

Reaction conditions: $\mathrm{O}_{2}: \mathrm{C}_{3} \mathrm{H}_{8}: \mathrm{He}$ molar ratio $=1: 2: 27$, total flow rate $=30 \mathrm{~cm}^{3} \mathrm{~min}^{-1}$, reaction time $=10 \mathrm{~min}$
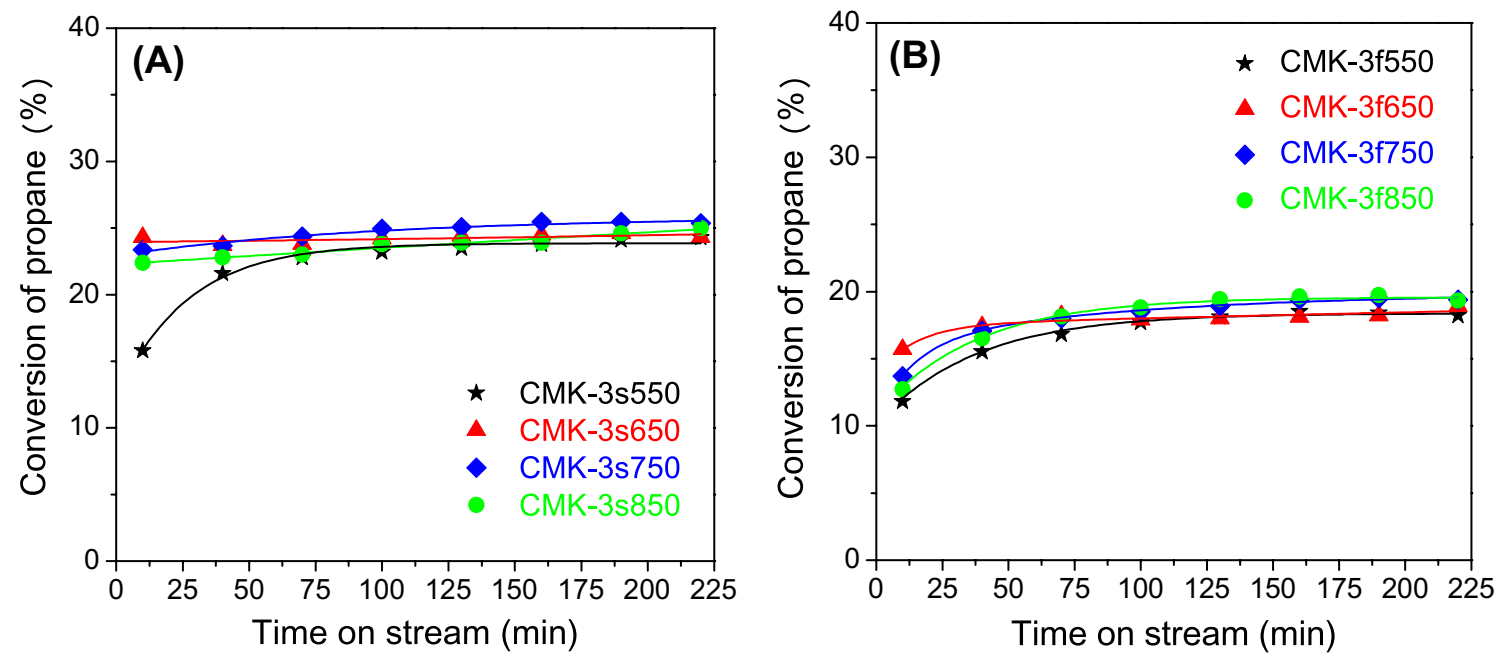

Fig. 7 Variations in propane conversion vs. time-on-stream at $450{ }^{\circ} \mathrm{C}$ over CMK-3s (a) and CMK-3f (b) catalysts 

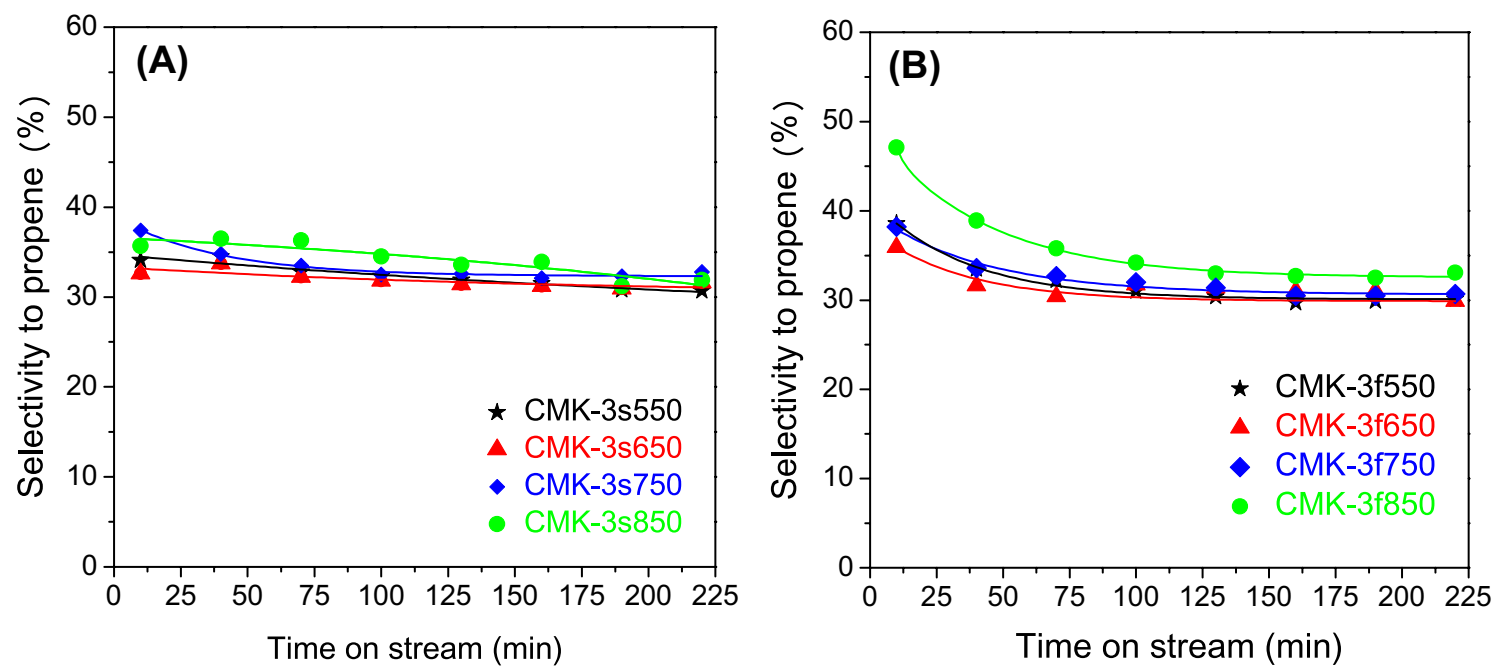

Fig. 8 Variations in selectivity to propene versus time-on-stream at $450{ }^{\circ} \mathrm{C}$ over CMK-3s (a) and CMK-3f (b) catalysts
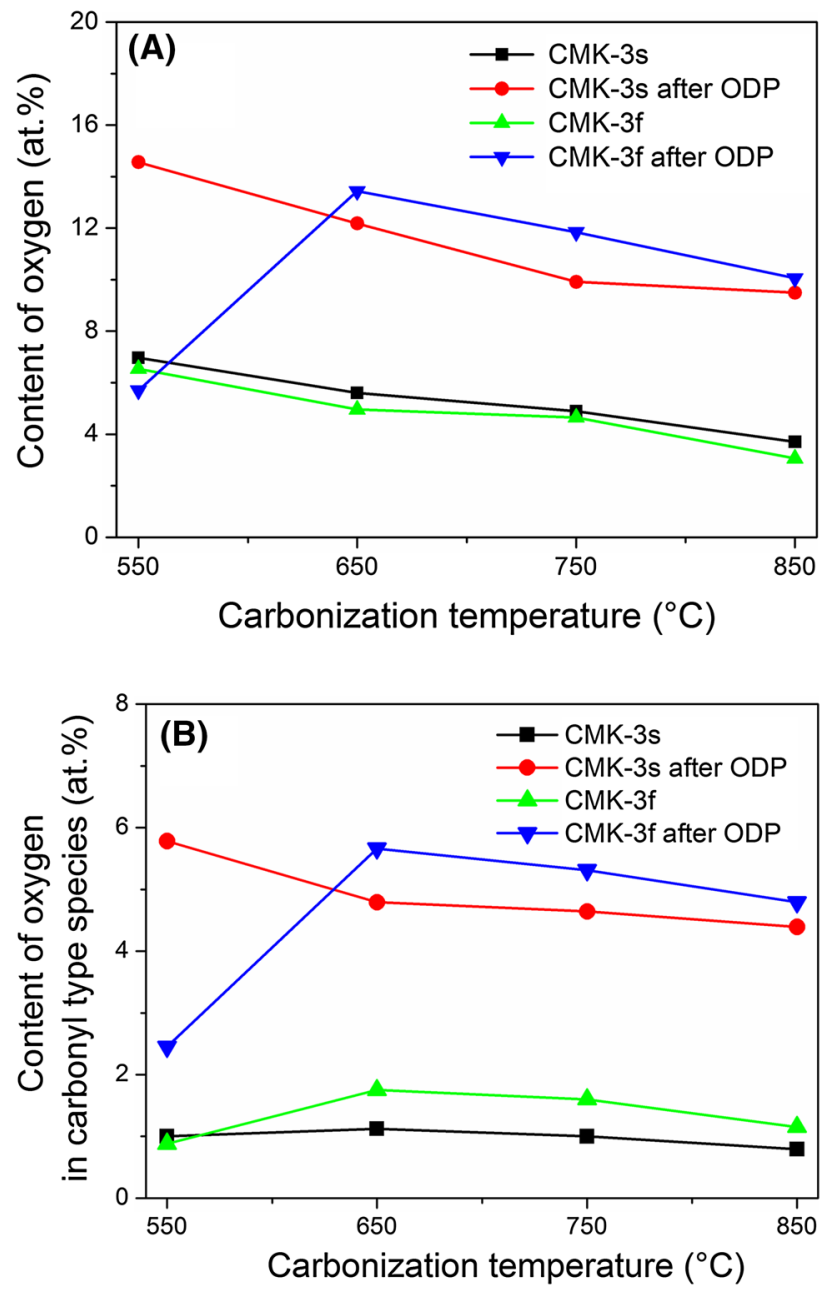

Fig. 9 Differences in content of all O species (a) and O in carbonyltype groups (b) on the surface of CMK-3 carbon replicas before and after the catalytic reaction detected by XPS

\section{Conclusions}

Mesoporous CMK-3 carbons based on sucrose and poly(furfuryl alcohol) precursors after carbonization at four different temperatures were investigated as catalysts in the oxidative dehydrogenation of propane to propene. The physicochemical characterization showed that both series of the synthesized carbon replicas had similar uniform, hexagonally ordered mesoporous structure forced by the SBA-15 template. The application of two various carbon precursors influenced however the porosity of the final CMK-3 materials. The catalysts prepared from the sucrose precursor exhibited the higher specific surface area and larger pore volume (including microporosity). On the other hand, over the poly(furfuryl alcohol)-derived carbon replicas slightly higher concentration of carbonyl-type groups was observed by XPS. This reflected in the higher specific activity of the CMK-3f materials in the ODP reaction. In most cases, after the initial period of reaction (about $60 \mathrm{~min}$ on stream), the steady state was achieved, and both conversion and selectivity were stabilised at the constant level.

Acknowledgements This work was supported by the National Science Centre under the Grant No. 2013/09/B/ST5/03419. The research was partially carried out with the equipment purchased thanks to the financial support of the European Regional Development Fund in the framework of the Polish Innovation Economy Operational Program (contract No. POIG.02.01.00-12-023/08).

Open Access This article is distributed under the terms of the Creative Commons Attribution 4.0 International License (http:// creativecommons.org/licenses/by/4.0/), which permits unrestricted use, distribution, and reproduction in any medium, provided you give appropriate credit to the original author(s) and the source, provide a link to the Creative Commons license, and indicate if changes were made. 


\section{References}

1. J.J.H.B. Sattler, J. Ruiz-Martinez, E. Santillan-Jimenez, B.M. Weckhuysen, Chem. Rev. 114, 10613 (2014)

2. M. Bhasin, J.H. McCain, B.V. Vora, T. Imai, P.R. Pujado, Appl. Catal. A 221, 397 (2001)

3. D. Sanfilippo, CatTech 4, 56 (2000)

4. F. Cavani, N. Ballarini, A. Cericola, Catal. Today 127, 113 (2007)

5. F. Cavani, F. Trifiro, Catal. Today 24, 307 (1995)

6. P. Michorczyk, P. Kuśtrowski, P. Niebrzydowska, A. Wach, Appl. Catal. A 445-446, 321 (2012)

7. L. Liu, Q.-F. Deng, Y.-P. Liu, T.-Z. Ren, Z.-Y. Yuan, Catal. Commun. 16, 81 (2011)

8. L. Liu, Q.-F. Deng, B. Agula, X. Zhao, T.-Z. Ren, Z.-Y. Yuan, Chem. Commun. 47, 8334 (2011)

9. A. Węgrzyniak, S. Jarczewski, A. Wach, E. Hędrzak, P. Kuśtrowski, P. Michorczyk, Appl. Catal. A 508, 1 (2015)

10. S. Jarczewski, M. Drozdek, A. Wach, B. Dudek, P. Kuśtrowski, M.E. Casco, F. Rodríguez-Reinoso, Catal. Lett. 146, 1231 (2016)

11. G. Mestl, I. Maksimova, N. Keller, V.V. Roddatis, R. Schlogl, Angew. Chem. Int. Ed. 40, 2066 (2001)

12. D.S. Su, J.J. Delgado, X. Liu, D. Wang, R. Schlögl, L. Wang, Z. Zhang, Z. Shan, F.-S. Xiao, Chem. Asian J. 4, 1108 (2009)

13. N. Keller, N.I. Maksimova, V.V. Roddatis, M. Schur, G. Mestl, Y.V. Butenko, V.L. Kuznetsov, R. Schlögl, Angew. Chem. Int. Ed. 41, 1885 (2002)
14. P. Kuśtrowski, P. Michorczyk, L. Chmielarz, Z. Piwowarska, B. Dudek, J. Ogonowski, R. Dziembaj, Termochim. Acta 471, 26-32 (2008)

15. W. Shen, Z. Li, Y. Liu, Recent Pat. Chem. Eng. 1, 27 (2008)

16. P. Michorczyk, J. Ogonowski, K. Zeńczak, J. Mol. Catal. A 349, $1(2011)$

17. S. Jun, S.H. Joo, R. Ryoo, M. Kruk, M. Jaroniec, Z. Liu, T. Ohsuna, O. Teresaki, J. Am. Chem. Soc. 122, 10712 (2000)

18. J.A. Botas, D.P. Serrano, P. Pizarro, G. Gomez, 18th WHEC 2010, Essen, 16-21 May 2010, 243-248.

19. C. Moreno-Castilla, M.V. Lopez-Ramon, F. Carrasco-Marin, Carbon 38, 1995 (2000)

20. C. Weidenthaler, A.H. Lu, W. Schmidt, F. Schüth, Microporous Mesoporous Mater. 88, 238 (2006)

21. S. Utgenannt, F. Hansen, O. Klepel, S. Jarczewski, A. Wach, P. Kuśtrowski, Catal. Today 249, 38 (2015)

22. K. Machowski, P. Natkański, A. Białas, P. Kuśtrowski, J. Therm. Anal. Calorim. 126, 1322 (2016)

23. P. Niebrzydowska, R. Janus, P. Kuśtrowski, S. Jarczewski, A. Wach, A.M. Silvestre-Albero, F. Rodríguez-Reinoso, Carbon 64, 252 (2013)

24. P. Janus, R. Janus, P. Kuśtrowski, S. Jarczewski, A. Wach, A.M. Silvestre-Albero, F. Rodríguez-Reinoso, Catal. Today 235, 201 (2014) 